\title{
Bur open Exploring adaptations to the modified shuttle walking test
}

\author{
Kate Woolf-May, ${ }^{1}$ Steve Meadows ${ }^{2}$
}

To cite: Woolf-May K, Meadows S. Exploring adaptations to the modified shuttle walking test. BMJ Open 2013;2:e002821. doi:10.1136/bmjopen-2013002821

\section{- Prepublication history for this paper are available online. To view these files please visit the journal online (http://dx.doi.org/10.1136/ bmjopen-2013-002821).}

Received 2 March 2013 Revised 14 April 2013 Accepted 19 April 2013

This final article is available for use under the terms of the Creative Commons Attribution Non-Commercial 2.0 Licence; see http://bmjopen.bmj.com

${ }^{1}$ Department of Sport Science, Tourism and Leisure, Canterbury Christ Church University, Canterbury, Kent, UK ${ }^{2}$ School of Sport \& Exercise Sciences, University of Kent, Chatham Maritime, Kent, UK

\footnotetext{
Correspondence to Dr Kate Woolf-May; kate.woolf-may@canterbury. ac.uk
}

\begin{abstract}
Objective: The $10 \mathrm{~m}$ modified shuttle walking test (MSWT) is recommended to determine the functional capacity in older individuals and for patients entering cardiac rehabilitation. Participants are required to negotiate around cones set $1 \mathrm{~m}$ from the end markers. However, consistent comments indicate that for some individuals manoeuvring around the cones can be quite difficult. Therefore, the objective of this study was to explore differences within and between noncardiac and postmyocardial infarction (MI) males during MSWT with and without the cones.
\end{abstract}

Design: Comparative study.

Participants: 20 post-MI (64.8 \pm 6.6 , range 51-74 years) and 20 non-cardiac male controls (64.1 \pm 5.7 , range 52-74 years) participated.

Methods: Participants performed MSWT with and without cones. Throughout, the participants expired air, and the heart rate (bpm) (HR) and ratings of perceived exertion (RPE) were measured. Participant protocol preference was recorded verbatim.

Results: One-way analysis of variance found no significant difference in $\mathrm{V}_{2}$ peak (cones $20.4 \pm 5.1$ vs nocones $21.9 \pm 4.8 \mathrm{ml} / \mathrm{kg} / \mathrm{min}, \mathrm{p}=0.197$ ) or distance ambulated (cones $631.8 \pm 132.9 \mathrm{~m}$ vs no-cones $662.4 \pm 164.1 \mathrm{~m}$, $\mathrm{p}=0.371$ ) between protocols or groups. Analysis comparing lines of regression showed a significant trajectory difference in $\mathrm{VO}_{2}(\mathrm{ml} / \mathrm{kg} / \mathrm{min})(\mathrm{p}<0.01)$ between protocols with higher $H R(p<0.01)$ and respiratory exchange ratio (RER, $p<0.001)$ values during cones. RPEs were higher for post-Mls versus controls during both protocols $(p<0.05)$. Post-Mls taking $\beta$-blockers produce significantly lower HR values. The $\chi^{2}$ analysis found no significant difference in protocol preference (no-cones: all $n=25,63 \%$; post-Mls $n=13,65 \%$; and controls $n=12,60 \%$ ).

Conclusions: Post-Mls found both protocols subjectively harder than controls with no significant difference in the $\mathrm{VO}_{2}$ peak. However, both groups worked at a lesser percentage of their anaerobic threshold during no-cones protocol as indicated by lower RER values. Importantly, for the post-Mls, this would reduce their risk of functional impairment. Therefore, though more research is required, indicators at present are more favourable for the use of the no-cones with post-Mls.

\section{INTRODUCTION}

It is recommended that patients entering cardiac rehabilitation (CR) should be

\section{ARTICLE SUMMARY}

Article focus

- The aim of the study was to explore whether removing the cones at each end of the $10 \mathrm{~m}$ modified shuttle walking test (MSWT) course resulted in any difference in participant performance and/or preference.

- Since MSWT is used on older and cardiac populations, the aim was also to see how these factors might differ between- and within-groups of male post-myocardial infarction patients and non-cardiac controls.

\section{Key messages}

- Post-myocardial infarctions (MIs) found both protocols subjectively harder than the noncardiac male controls by reporting higher ratings of perceived exertion values.

- Irrespective of group, participants worked at a lower percentage of their anaerobic threshold (AT) during the no-cones protocol with no significant effect on the $\mathrm{VO}_{2}$ peak.

- Most significantly, for post-Mls, since there was no significant difference in the $\mathrm{VO}_{2}$ peak between the protocols and AT was reached at a later stage during the no-cones protocol, this would be of benefit to the post-Mls by reducing their risk of any functional impairment without altering the overall end result of the test.

- Although there have been some interesting findings from this study, further research is still required before the no-cones protocol can be reliably employed.

measured for functional capacity both before and after exercise training intervention. ${ }^{1-3}$ In a clinical setting, it is often not practical and/or possible to conduct tests of maximal oxygen uptake $\left(\mathrm{VO}_{2} \max , \mathrm{ml} / \mathrm{kg} / \mathrm{min}\right)$ for reasons of time, safety, access to specialised equipment, tester expertise and funding. Therefore, field tests are often employed. Field tests generally achieve measures of peak oxygen uptake $\left(\mathrm{VO}_{2}\right.$ peak, $\mathrm{ml} / \mathrm{kg} / \mathrm{min}$ ) rather than $\mathrm{VO}_{2}$ max. $\mathrm{VO}_{2}$ peak usually coincides with onset of symptoms of fatigue, such as breathlessness and/or leg fatigue, and/or possible angina symptoms. This measure of functional capacity is useful in establishing 
benchmark values of fitness and/or onset of ischaemic threshold. During this assessment, the exercise threshold achieved reflects a patient's risk category ${ }^{4}$; future health prediction, ${ }^{56}$ is used in establishing appropriate exercise prescription intensity levels, progression within an exercise programme and as an outcome measure. ${ }^{7}$ The incremental modified shuttle walking test (MSWT), originally developed for chronic obstructive pulmonary disease patients, ${ }^{8}$ is now recommended for older and symptomatic individuals, such as cardiac patients, ${ }^{1}{ }^{3}$ including coronary artery bypass graft (CABG) patients, ${ }^{9-11}$ those with pacemakers ${ }^{12}$ and heart failure. ${ }^{13}{ }^{14}$ Distance covered during MSWT has been found to correlate highly with direct measures of $\mathrm{VO}_{2}$ max in CABG patients ${ }^{11}$ as well as distance walked and $\mathrm{VO}_{2}$ peak during treadmill walking in patients with heart failure. ${ }^{13}{ }^{15}$ MSWT, therefore, offers a practical, economic and valid assessment of the $\mathrm{VO}_{2}$ peak without resorting to complex physiological measures of gas analysis. $^{11}$

The rationale for this present study emerged from consistent anecdotal comments made by CR patients about difficulty manoeuvring around the cones at each end of the MSWT $10 \mathrm{~m}$ course (see figure 1). This consistent comment led researchers to formally explore whether MSWT might be better performed with the removal of these cones and simply using tape on the floor to denote the distances to be achieved. ${ }^{16}$ Therefore, the aim was to conduct a simple study exploring comparisons between and within cardiac and noncardiac participants during MSWT, with and without the cones, in order to determine whether participants better performed and/or preferred this alternative protocol.

\section{METHODS}

Ethical approval for the study was provided by The Faculty of Social and Applied Science Research Ethics Committee at Canterbury Christ Church University, reference $10 /$ SAS $/ 045$.

\section{Participants}

Post-myocardial infarction (MI) males were recruited through the local community phase IV CR exercise classes. The non-cardiac volunteers were recruited from the Medway area, UK, through word of mouth and posters placed within the University of Kent at Medway. All volunteers were given a Participant Information Sheet and interested individuals were asked to complete a Health and Physical Activity (PA) Screening Questionnaire. The post-MIs were required to be 'uncomplicated' and stable, be at phase IV level and be taking standard medications (such as statin, $\beta$-blocker, aspirin and ACE inhibitor). Potential controls were to be free of any cardiac disease and/or event or have a chronic medical condition and/or taking long-term medications. All participants were required to be nonsmoking, understand the nature of the study, aged between 50-75 years, be of similar PA level and free of any orthopaedic limitations during exercise. Participants that cleared the screening process were required to provide written informed consent and have written acknowledgement of their participation from their General Practitioner. Participants were free to withdraw from the study at any time without providing a reason.

\section{Protocol}

All testing was undertaken in the Exercise Rehabilitation Gym (ERG) at the University of Kent, Medway Campus, UK, under the supervision of a qualified British Association of Cardiac Preventative and Rehabilitation (BACPR) Phase IV instructor. All participants were required to make three separate visits to the ERG. The first was for familiarisation and the latter two for the actual data collection. While wearing the testing equipment, each participant was individually familiarised to both test protocols. ${ }^{11}$ The order was determined by computer randomisation. To ensure that participants were competent with both protocols, they went to around halfway and not to fatigue (reaching no more than level 7) with a break of around 8 min between each protocol. The latter two tests were for actual data collection and wherever possible, tests were performed at a similar time of day to control for circadian variation. ${ }^{17}$

\section{Pretest procedures and familiarisation}

Prior to each test, including familiarisation, each participant was seated and completed a Pretest Screening Form to ensure that on each testing occasion they were able and well enough to perform the test and had adhered to the pretest criteria. During the $24 \mathrm{~h}$ preceding assessments, participants were required not to undertake moderate to vigorous $\mathrm{PA} /$ exercise or consume alcohol, nor to eat and/or consume caffeine during the preceding $2 \mathrm{~h}$; drinking water was permitted; where relevant, participants were instructed to take their medications as usual.

Following satisfactory pretest screening, each participant was first measured for height and body mass using a stadiometer (Seca 220, Hamburg, Germany) and clinical scales (Seca 710, Hamburg, Germany), respectively. The participant then sat for 5 min and was measured for pre-exercise resting blood pressure (BP), using a stethoscope and sphygmomanometer (Yamasu Mercurial Sphygmomanometer 605P, Kenzmedico Co. Ltd, Japan), and heart rate (HR) using a Polar S810 HR monitor (Polar Electro Oy, Kempele, Finland). If no additional or acute physiological abnormalities were detected, participants proceeded to either MSWT protocol. Prior to each test, each participant was fitted with a face mask covering the nose and mouth (Hans Rudolph, Germany) connected to a portable gas analyser (Cosmed $\mathrm{K} \mathrm{b}^{2}$, Roma, Italy) to measure and record expired air parameters during the test. 
Figure 1 Layout of the modified shuttle walking test.

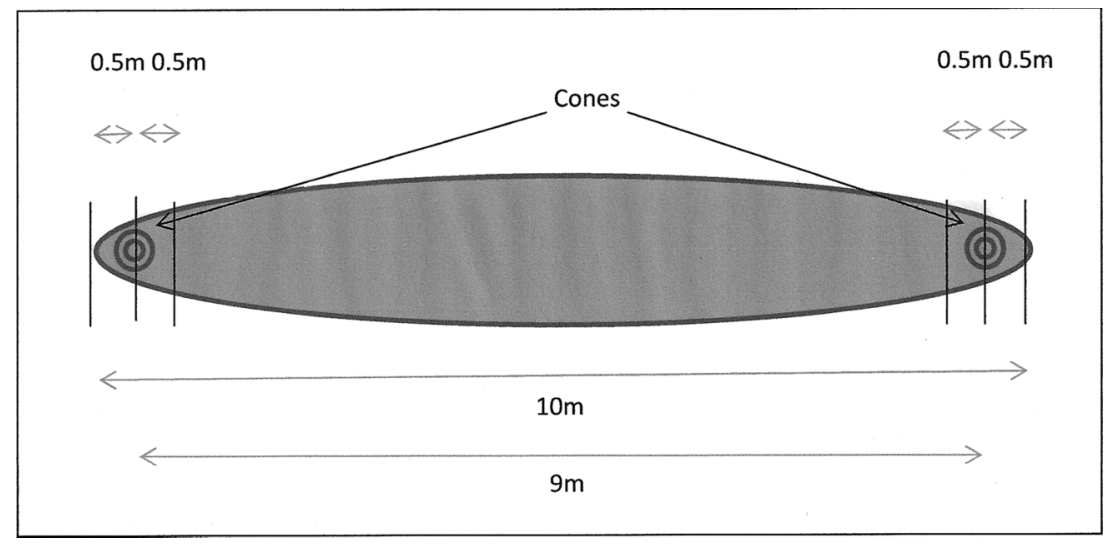

\section{MSWT}

The MSWT environment was well lit and ventilated, with a non-slippery flat floor. The $10 \mathrm{~m}$ course was marked out on the floor using masking tape and orange cones (for the cones, protocol only) (figure 1 and table 1).

During both MSWT protocols, participants were externally paced by prerecorded bleeps emitted as an audible signal played from a CD player. The timing of the bleeps indicate walking pace and participants were required to reach the $1 \mathrm{~m}$ mark at the end of the $10 \mathrm{~m}$ course in time to each bleep. The test started with a slower speed and fewer shuttles. The starting pace was $0.5 \mathrm{~m} / \mathrm{s}$ and each level was $1 \mathrm{~min}$. After each minute, the speed increased by $0.17 \mathrm{~m} / \mathrm{s}$, indicated by a treble bleep resulting in an increase in the number of shuttles per minute (table 1). At the end of each level, an enlarged A3 6-20 rating of perceived exertion (RPE) scale ${ }^{18}$ was shown to each participant to gain their subjective feelings of exertion. The test was terminated if patients felt too breathless and/or fatigued to continue, showed signs of physical injury and/or distress (as indicated by measures of HR, respiratory exchange ratio (RER) and RPE) and/ or no longer wished to continue or failed to reach within $1 \mathrm{~m}$ of the end marker on two consecutive

\begin{tabular}{|c|c|c|c|}
\hline Level & $\begin{array}{l}\text { Speed } \\
(\mathrm{m} / \mathrm{h})\end{array}$ & $\begin{array}{l}\text { Speed } \\
(\mathrm{km} / \mathrm{h})\end{array}$ & $\begin{array}{l}\text { Shuttles (each shuttle } \\
\text { equals } 10 \mathrm{~m} \text { ) }\end{array}$ \\
\hline 1 & 1.1 & 1.8 & $1-3$ \\
\hline 2 & 1.5 & 2.4 & $4-7$ \\
\hline 3 & 1.9 & 3.1 & $8-12$ \\
\hline 4 & 2.3 & 3.7 & $13-18$ \\
\hline 5 & 2.6 & 4.2 & $19-25$ \\
\hline 6 & 3.0 & 4.8 & $26-33$ \\
\hline 7 & 3.4 & 5.5 & $34-42$ \\
\hline 8 & 3.8 & 6.1 & $43-52$ \\
\hline 9 & 4.2 & 6.8 & $53-63$ \\
\hline 10 & 4.5 & 7.2 & $64-75$ \\
\hline 11 & 4.9 & 7.9 & $76-88$ \\
\hline 12 & 5.3 & 8.5 & 89-102 \\
\hline
\end{tabular}

MSWT,modified shuttle walking test. occasions. Verbal indication was given by the researcher if the participant had not reached the $9 \mathrm{~m}$ marker on time, providing the participant an opportunity to catch up. Once the test was completed, the total distance walked and end RPE were recorded. After removal of the mask and portable $\mathrm{VO}_{2}$ analyser, while $\mathrm{HR}$ was still being monitored, participants performed a $10 \mathrm{~min}$ walking cool-down to reduce the risk of an adverse event. Post-exercise HR and BP were measured before participants left the test environment to ensure that these returned to pre-exercise levels. At this point and after the final MSWT test, each participant was asked which of the two protocols they preferred and to provide a short reason why. Responses were recorded verbatim.

\section{Data analysis}

Statistical analysis was carried out using the Minitab statistical package (V.16), with a 5\% level of significance and variability within a distribution of $1 \mathrm{SD}($ mean $\pm \mathrm{SD})$. Greater $\mathrm{VO}_{2}$ peak measures are strongly linked to reduced mortality and morbidity, ${ }^{19}$ and in the prognosis of cardiac patients. ${ }^{20}$ Therefore, participant numbers at $5 \% \alpha$ and $90 \%$ power were based on a mean difference in the $\mathrm{VO}_{2}$ peak of $2.5 \pm 3.0(\mathrm{ml} / \mathrm{kg} / \mathrm{min})$ between protocols, which required $\mathrm{n}=17$ participants to perform each protocol. To account for attrition, $\mathrm{n}=20$ participants were recruited to each group. Therefore, any significant difference between protocols in this factor was important in determining the tests' ability to predict future health status.

Inter- and intra-group differences were compared by one-way analysis of variance. Analysis comparing two lines of regression was employed to determine the difference between the two MSWT protocols and between groups in $\mathrm{VO}_{2}(\mathrm{ml} / \mathrm{kg} / \mathrm{min})$, HR (bpm), RER and RPE. Pearson's Product Moment correlation and multiple regression analyses were employed to determine relationships between factors. Non-parametric alternatives were employed where data failed to be normally distributed. The $\chi^{2}$ test was used to compare differences in nominal data. 
Table 2 Participant characteristics mean \pm SD (range)

\begin{tabular}{|c|c|c|}
\hline Characteristics & Post-Mls, $n=20$ & Controls $n=20$ \\
\hline Age (years) & $64.8 \pm 6.6(51-74)$ & $64.1 \pm 5.7(52-74)$ \\
\hline Height $(\mathrm{cm})$ & $175.9 \pm 5.8(165-185)$ & $175.5 \pm 6.7(164-186)$ \\
\hline Body mass (kg) & $87.7 \pm 13.2(64-111)^{*}$ & $82.0 \pm 11.9(62-102)$ \\
\hline BMI $\left(\mathrm{kg} / \mathrm{m}^{2}\right)$ & $28.3 \pm 3.8(20.5-35.5)^{\star}$ & $26.6 \pm 3.0(21.6-31.9)$ \\
\hline \multicolumn{3}{|l|}{ Pre-exercise resting } \\
\hline $\mathrm{SBP}(\mathrm{mm} \mathrm{Hg})$ & $122.4 \pm 19.0(100-180)^{*}$ & $133.6 \pm 15.7(106-170)$ \\
\hline Cones & $124.8 \pm 16.1(98-158)$ & $133.1 \pm 15.7(110-170)$ \\
\hline \multicolumn{3}{|l|}{ No-cones } \\
\hline \multicolumn{3}{|l|}{ Pre-exercise resting } \\
\hline $\mathrm{DBP}(\mathrm{mm} \mathrm{Hg})$ & $79.8 \pm 8.7(64-96)$ & $85.1 \pm 10.0(70-110)$ \\
\hline Cones & $79 \pm 10.3(60-100)$ & $84.2 \pm 8.0(70-98)$ \\
\hline \multicolumn{3}{|l|}{ No-cones } \\
\hline \multicolumn{3}{|l|}{ Pre-exercise resting } \\
\hline HR (bpm) & $57.8 \pm 7.6(36.6-69.1) \dagger$ & $74.1 \pm 17.2(45.4-109.8)$ \\
\hline Cones & $57.5 \pm 6.2(40.8-70.1) \dagger$ & $68.8 \pm 11.8(44.0-90.9)$ \\
\hline \multicolumn{3}{|l|}{ No-cones } \\
\hline \multicolumn{3}{|l|}{ Weekly PA } \\
\hline 30 min sessions at moderate intensity & $4.3 \pm 1.8(1-7) \dagger$ & $3.0 \pm 2.3(0-7)$ \\
\hline 20 min sessions at vigorous intensity & $2.4 \pm 2.0(0-6)$ & $1.7 \pm 1.5(0-5)$ \\
\hline
\end{tabular}

\section{RESULTS}

\section{Participant characteristics}

Post-MIs and controls were matched for age and height, but post-MIs possessed significantly greater body mass (kg) and subsequent BMI than controls, with both groups within the overweight category (table 2$).{ }^{21}$ Post-MIs were

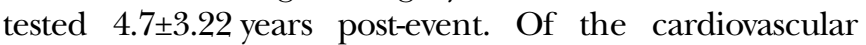
disease (CVD) risk factors, 'family history of CVD', high cholesterol, diabetes, hypertension and obesity, post-MIs possessed a total of $n=18$ and controls $n=11$.

\section{Medications}

Analysis showed that post-MIs taking $\beta$-blockers had significantly reduced resting $\mathrm{HR}(\mathrm{bpm})$ ( $\beta$-blockers $\mathrm{n}=19$, $57.7 \pm 7.0$ vs $\mathrm{n}=21,70.8 \pm 14.7 \mathrm{bpm}, \mathrm{F}=25.04, \mathrm{p}<0.001)$ and lower HR (bpm) during both protocols (see section post-MIs vs controls). Those post-MIs taking $\beta$-blockers were also taking statins, and therefore statins showed a similar statistical effect. Too few of the other medications had a statistically significant effect on any of the measured variables.

\section{Results not differentiated by group \\ Cones vs no-cones}

The order in which the participants performed each protocol had no significant effect upon any of the measured variables. Although the mean distance during no-cones was $30 \mathrm{~m}$ further compared with cones, the difference was not significant (cones 631.8 \pm 132.9 vs no-cones $662.4 \pm 164.1 \mathrm{~m}, \mathrm{~F}=0.81, \mathrm{p}=0.371)$. Furthermore, even though a greater number of the participants $(n=25,63 \%)$ preferred no-cones compared with cones $(\mathrm{n}=15,37 \%)$, this too was not significantly different. Preference had no significant effect on the distance ambulated for either protocol $(\mathrm{F}=0.87, \mathrm{p}=0.354)$. Typical comments given by those participants who preferred no-cones related to ease of turning and perception of not having to walk as far. Examples were: 'Difficult to manoeuvre around cone', 'Don't have to walk as far and easier to turn', 'Not so far to go on turn; easier to just turn', 'Can walk straighter and it saves a foot at each end', suggesting that some participants perceived they did not have to walk as far. The main comments from those who preferred the cones indicated that they liked having the cones as a target to aim for, and found the turning easier. Analysis also showed that body mass, height and BMI did not significantly $(p>0.05)$ influence preference or performance. However, those who preferred the no-cones were significantly younger (cones $\mathrm{n}=15,66.1 \pm 6.9$ vs no-cones $\mathrm{n}=25,63.4 \pm 5.4$ years, $\mathrm{F}=3.94$, $\mathrm{p}=0.05)$. The negative correlation between age and distance ambulated $(\mathrm{R}=-0.491, \mathrm{p}<0.001)$ indicated that younger participants walked further, regardless of the group they were in. Not all participants achieved all levels during MSWT (table 3).

Table 3 Level achieved by participants during MSWT for different protocols

\begin{tabular}{lllllll}
\hline Level & $\mathbf{1 - 7}$ & $\mathbf{8}$ & $\mathbf{9}$ & $\mathbf{1 0}$ & $\mathbf{1 1}$ & $\mathbf{1 2}$ \\
\hline Cones & 40 & 40 & 30 & 20 & 10 & 1 \\
No-cones & 40 & 38 & 31 & 21 & 12 & 4 \\
\hline
\end{tabular}

MSWT,modified shuttle walking test. 


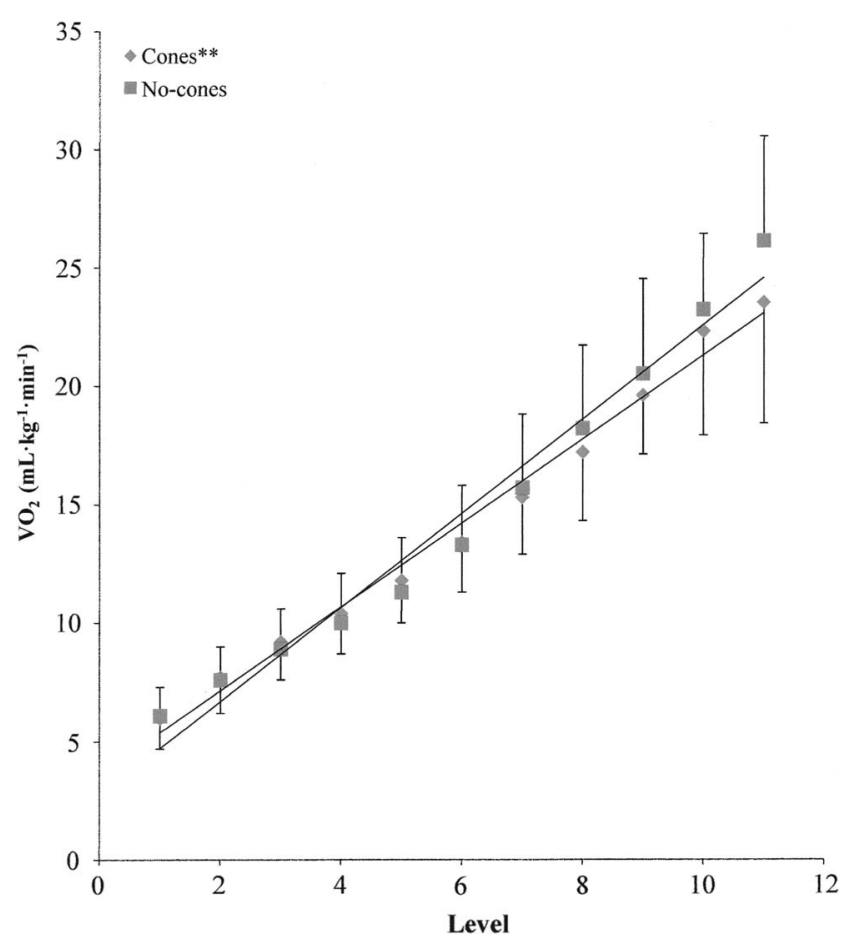

Figure 2 The $\mathrm{VO}_{2}(\mathrm{ml} / \mathrm{kg} / \mathrm{min})$ versus modified shuttle walking test-level relationship for the different protocol.

A significant difference was found in the $\mathrm{VO}_{2}(\mathrm{ml} / \mathrm{kg} /$ min) versus MSWT-level relationship ( $\mathrm{F}=10.26 \mathrm{p}<0.01$, figure 2) (level 12 excluded as too few numbers); HR (bpm) (levels 1-10) $(\mathrm{F}=7.61 \mathrm{p}<0.01$, figure 3) and RER (levels 1-10) (F=41.11, $\mathrm{p}<0.001$, figure 4) versus MSWT-level relationships were consistently lower than the no-cones protocol. There were no significant

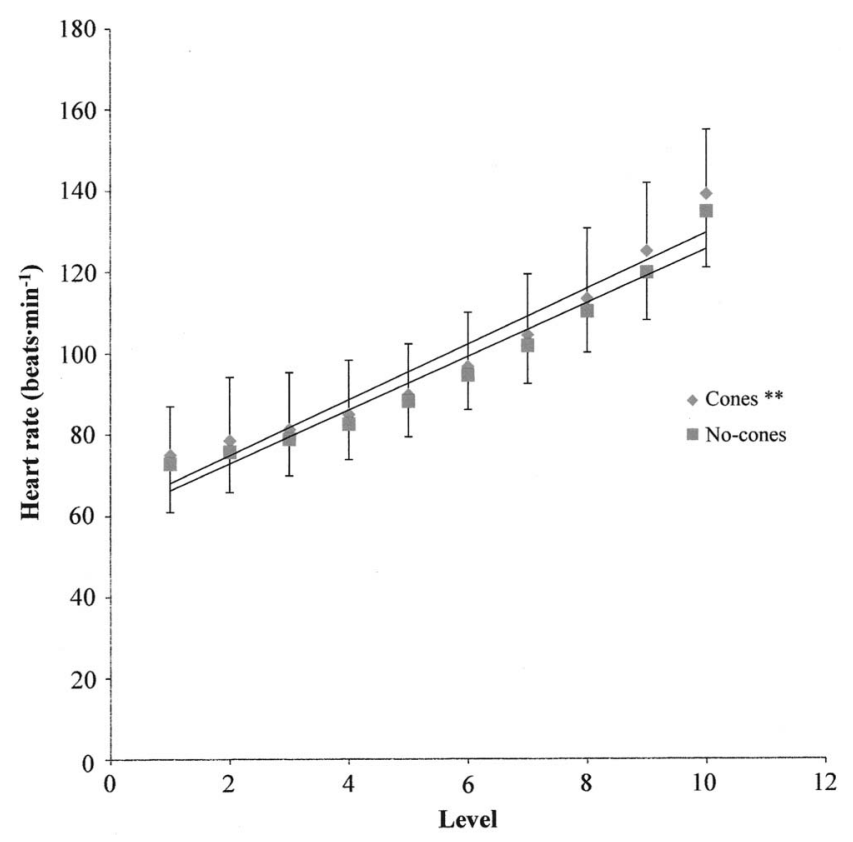

Figure 3 The heart rate (bpm) versus modified shuttle walking test-level relationship for the protocols.

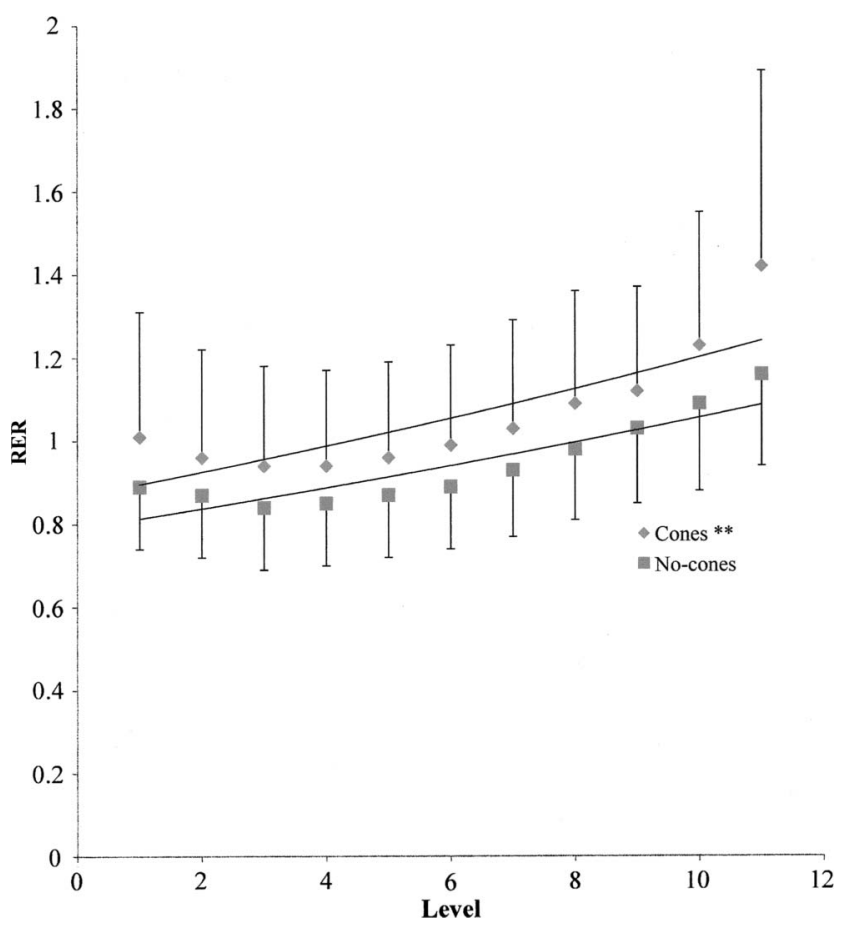

Figure 4 Respiratory exchange ratio versus modified shuttle walking test-level relationship for the different protocols.

differences in the RPE or $\mathrm{VO}_{2}$ peak (cones, 20.4 \pm 5.1 vs no-cones $21.9 \pm 4.8 \mathrm{ml} / \mathrm{kg} / \mathrm{min}, \mathrm{F}=1.69$, $\mathrm{p}=0.197$ ).

\section{Post-myocardial infarctions}

Although post-MIs walked a mean of $44.4 \mathrm{~m}$ further during the no-cones, this was not statistically significant (cones, 613.0 \pm 114.0 vs no-cones, $657.9 \pm 167.8 \mathrm{~m}, \mathrm{~F}=0.79$, $\mathrm{p}=0.380)$. There was no significant difference in the $\mathrm{VO}_{2}$ peak between protocols (cones, 19.3 \pm 4.9 vs no-cones, $21.1 \pm 5.0 \mathrm{ml} / \mathrm{kg} / \mathrm{min}, \mathrm{F}=1.29, \mathrm{p}=0.264) . \mathrm{VO}_{2}(\mathrm{ml} / \mathrm{kg} / \mathrm{min})$ and RER versus MSWT-level relationship were significantly higher and lower for the no-cones $(\mathrm{F}=10.26 \mathrm{p}<0.01 ; \mathrm{F}=9.38$ $\mathrm{p}=0.002$, figure 5 and 6), respectively. However, HR (bpm) and RPE were not significantly different. Although $13(65 \%)$ post-MIs preferred no-cones versus $7(35 \%)$ cones, this was not significantly different. Not all post-MIs achieved all levels during MSWT (table 4).

\section{Controls}

The controls walked $15.7 \mathrm{~m}$ further during the no-cones compared with the cones, which was not statistically significant (cones, 651.1 \pm 120.8 vs no-cones $666.8 \pm 164.8 \mathrm{~m}$, $\mathrm{F}=0.11, \mathrm{p}=0.738)$. There was no significant differences in the $\mathrm{VO}_{2}$ peak (cones, $21.3 \pm 5.2$ vs no-cones, $22.7 \pm 4.6 \mathrm{ml} /$ $\mathrm{kg} / \mathrm{min}, \mathrm{F}=0.51, \mathrm{p}=0.478)$, or $\mathrm{VO}_{2}(\mathrm{ml} / \mathrm{kg} / \mathrm{min})$ and RPE versus MSWT-level relationship between protocols. However, the HR (bpm) and RER relationships were significantly higher during the cones $(\mathrm{F}=11.34, \mathrm{p}<0.001$, figure 7; $\mathrm{F}=35.93, \mathrm{p}<0.001$, figure 8 , respectively). Despite the majority of the controls preferring the no-cones (cones $\mathrm{n}=8,40 \%$ and no-cones $\mathrm{n}=12,60 \%$ ), 


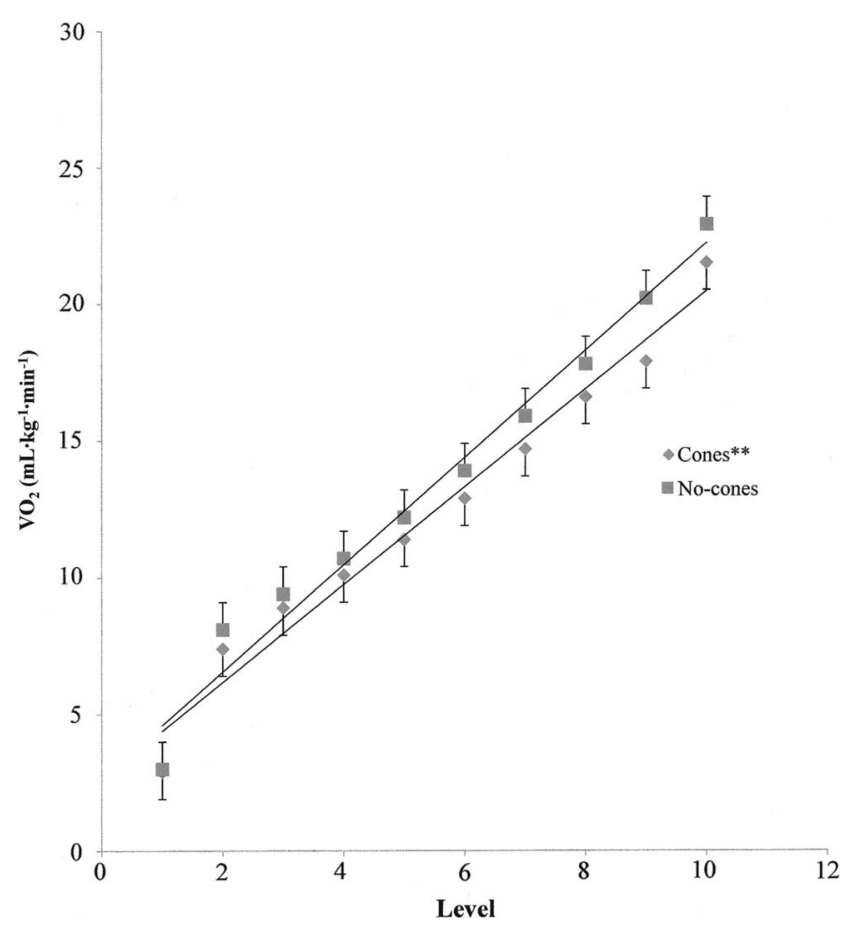

Figure 5 Post-myocardial infarctions $\mathrm{VO}_{2}(\mathrm{ml} / \mathrm{kg} / \mathrm{min})$ versus modified shuttle walking test-level relationship for the different protocols.

this again was not significantly different. Not all controls achieved all levels during MSWT (table 5).

\section{Post-Mls vs controls}

Cones

Although the controls walked a mean of $37.6 \mathrm{~m}$ further than post-MIs, this was not statistically significant

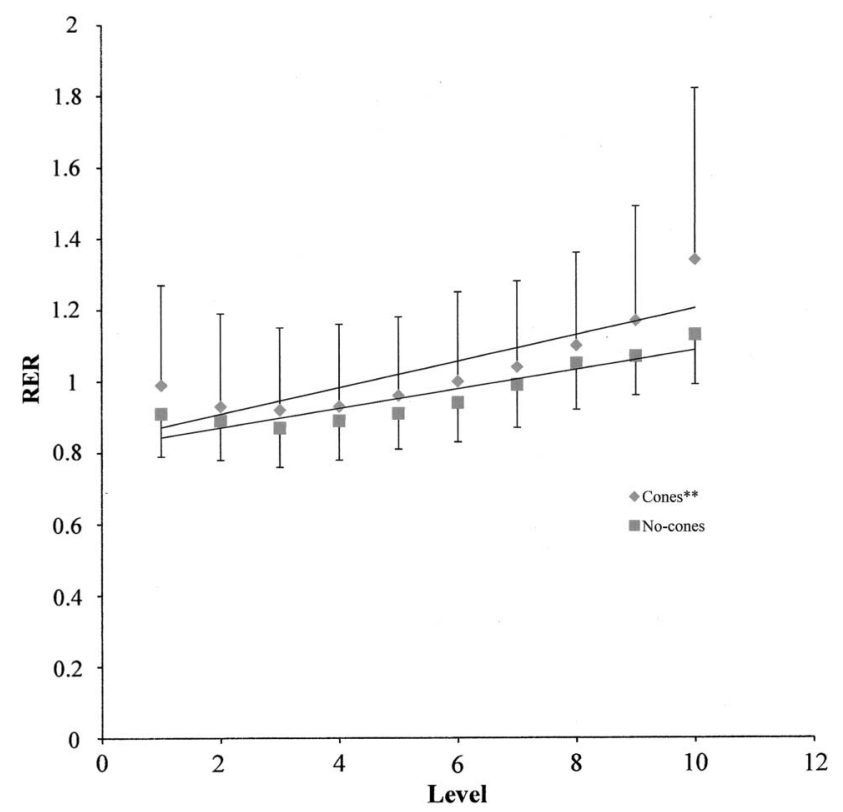

Figure 6 Post-myocardial infarctions respiratory exchange ratio versus modified shuttle walking test-level relationship for the different protocols.
(post-MIs， $613.5 \pm 144.0$ vs controls, $651.1 \pm 120.8 \mathrm{~m}$, $\mathrm{F}=0.77, \mathrm{p}=0.385$ ). Eight controls and seven post-MIs preferred the cones, which too was not significantly different. There was no significant difference in the $\mathrm{VO}_{2}(\mathrm{ml} /$ $\mathrm{kg} / \mathrm{min}$ ) or RER versus MSWT-level relationships between groups. However, HR (bpm) was significantly lower for post-MIs ( $\mathrm{n}=19$ taking $\beta$-blockers) versus controls $(\mathrm{F}=72.2, \mathrm{p}<0.001$; none were taking $\beta$-blockers $)$. RPE versus MSWT-level relationship values were significantly higher for post-MIs versus controls $(\mathrm{F}=4.78$, $\mathrm{p}=0.029$, figure 9).

\section{No-cones}

Controls walked a mean of $8.9 \mathrm{~m}$ further than post-MIs during the no cones, which was not statistically significant (post-MIs, $657.9 \pm 167.8$ vs controls, $666.8 \pm 164.8 \mathrm{~m}, \mathrm{~F}=0.03$, $\mathrm{p}=0.869)$. Twelve controls and 13 post-MIs preferred the no-cones, which too was not significantly different. There was no significant difference in the $\mathrm{VO}_{2}(\mathrm{ml} / \mathrm{kg} / \mathrm{min})$ versus MSWT-level relationship between groups. The HR (bpm) versus MSWT-level relationship was significantly lower in post-MIs versus controls $(\mathrm{F}=51.24, \mathrm{p}<0.001)$ and significantly higher for RER and RPE ( $F=23.51 \mathrm{p}<0.001$, figure $10 ; \mathrm{F}=4.78, \mathrm{p}=0.029$, figure 11 , respectively).

Extra data are available by emailing the first author.

\section{DISCUSSION}

Comments collected from those participants as to why they preferred the no-cones suggested that some participants perceived they did not have to walk as far, as they did not have to manoeuvre around the cones, which they found difficult to negotiate. Those who preferred the cones generally liked the cones as a target to aim for and found the turning easier. Anthropometric factors such as height and body mass, which might be expected to have some mechanical influence, were found not to have any statistically significant effect upon preference. Analysis did, however, reveal that the younger participants, regardless of group, preferred the no-cones. These participants tended to walk further, subsequently reaching faster walking speeds. The turning technique employed in the no-cones is more representative of a 'touch and turn', where participants touched the end tape with their foot and turned, whereas the cones requires participants to negotiate around the end cone within the $1 \mathrm{~m}$ space between the tape at the end (figure 1). At higher walking speeds, the latter might make turning difficult and partly explain why the

Table 4 Level achieved by post-Mls during MSWT for different protocols

\begin{tabular}{lllllll}
\hline Level & $\mathbf{1 - 7}$ & $\mathbf{8}$ & $\mathbf{9}$ & $\mathbf{1 0}$ & $\mathbf{1 1}$ & $\mathbf{1 2}$ \\
\hline Cones & 20 & 20 & 13 & 7 & 4 & 0 \\
No-cones & 20 & 18 & 15 & 9 & 5 & 2 \\
\hline \multicolumn{7}{l}{ MI, myocardial infarction; } \\
MSWT,modified shuttle walking test.
\end{tabular}




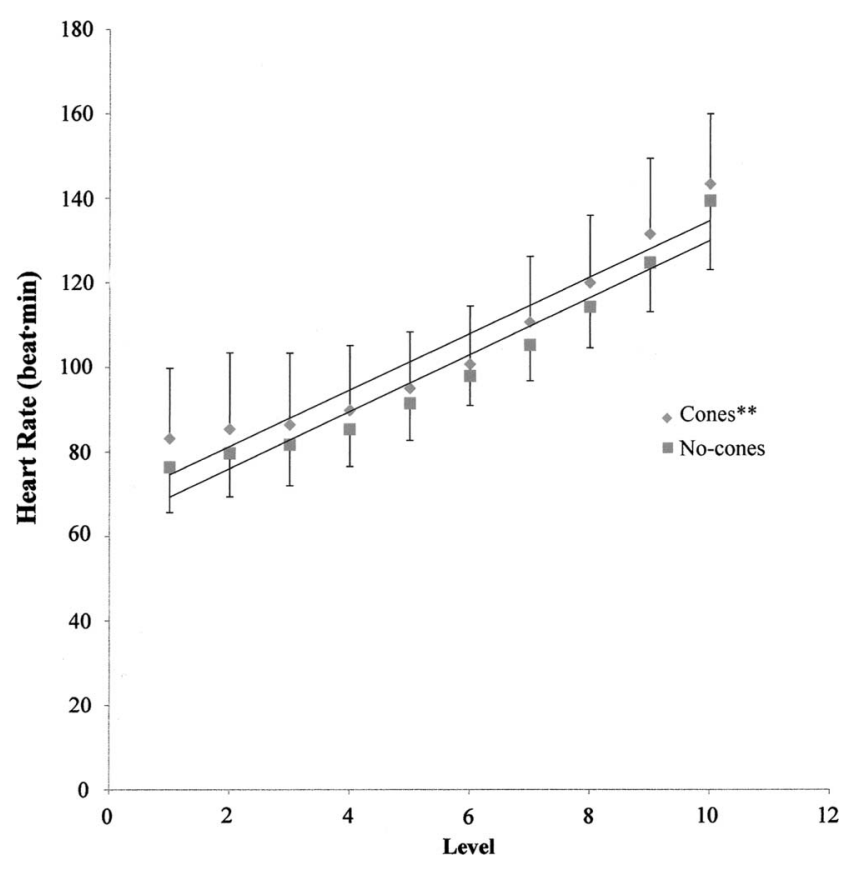

Figure 7 Controls heart rate (bpm) versus modified shuttle walking test-level relationship for the different protocols.

younger faster walkers preferred the no-cones. Although the majority of participants preferred the no-cones (all $\mathrm{n}=25,63 \%$; post-MIs $\mathrm{n}=13$, $65 \%$; controls $\mathrm{n}=12,60 \%$ ), this was not statistically significant. Retrospective secondary power analysis for nominal data showed that a majority of $68 \%$ were required to achieve statistical significance at $\mathrm{p}<0.05$. Since preference percentage was not far from this figure, it is likely that this factor was

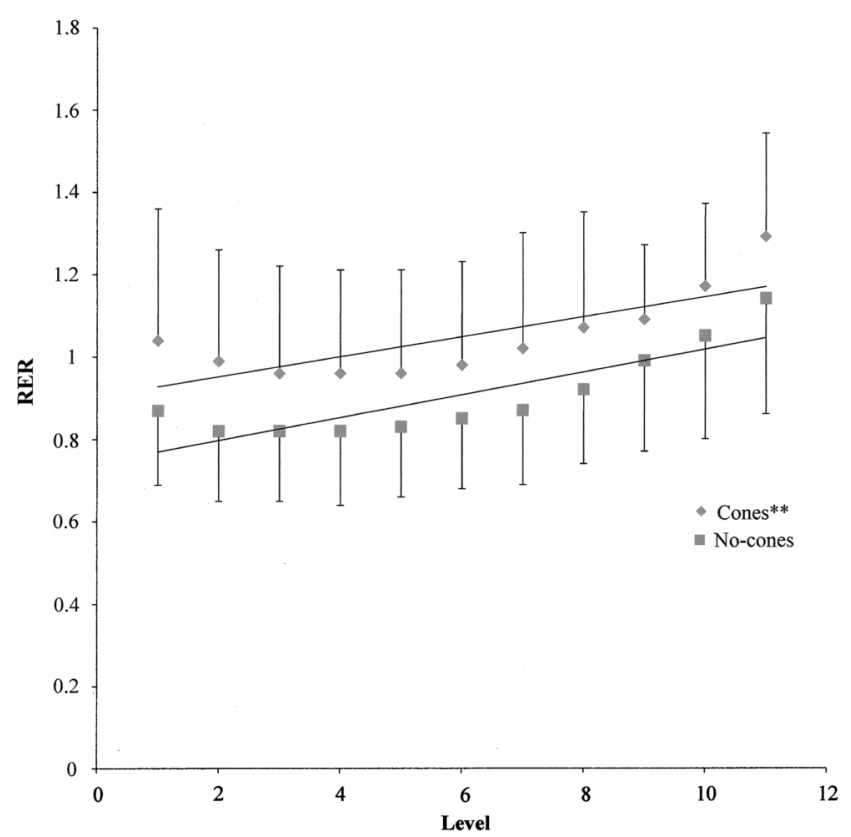

Figure 8 Controls respiratory exchange ratio versus modified shuttle walking test-level relationship for the different protocols.
Table 5 Level achieved by controls during MSWT for different protocols

\begin{tabular}{lllllll}
\hline Level & $\mathbf{1 - 7}$ & $\mathbf{8}$ & $\mathbf{9}$ & $\mathbf{1 0}$ & $\mathbf{1 1}$ & $\mathbf{1 2}$ \\
\hline Cones & 20 & 20 & 17 & 13 & 6 & 1 \\
No-cones & 20 & 20 & 16 & 12 & 7 & 2 \\
\hline \multicolumn{7}{l}{ MSWT, modified shuttle walking test. }
\end{tabular}

underpowered and would be worth exploring further in a future study.

The relationship between $\mathrm{VO}_{2}$ peak with mortality and morbidity, ${ }^{19}$ and prognosis in cardiac patients ${ }^{20}$ is an important factor in determining an individual's health status. Since there was no significant difference between the two protocols in the $\mathrm{VO}_{2}$ peak, this would suggest that the no-cones is as effective at determining health outcomes as the current cones protocol.

HR values (for those participants not taking $\beta$-blockers) and RER values were significantly higher during the cones, indicating that participants worked at a higher percentage of their anaerobic threshold (AT) ${ }^{22}$ Although there is debate about the best indirect marker of AT, a recent study by Solberg $e t a l,{ }^{23}$ looking at a range of $\mathrm{VO}_{2}$ parameters, found the marker of RER $\geq 1.0$ to be a reliable indicator of AT. For the cones, participants reached AT $(\mathrm{RER} \geq 1.0)$ at lower walking speeds. This differed between protocols by around one MSWT-level (figures 4, 6 and 8) and between groups by around 2 levels (figure 11). While this may not be too much of an issue for non-cardiac populations, for the post-MIs this is of importance. There is a potential

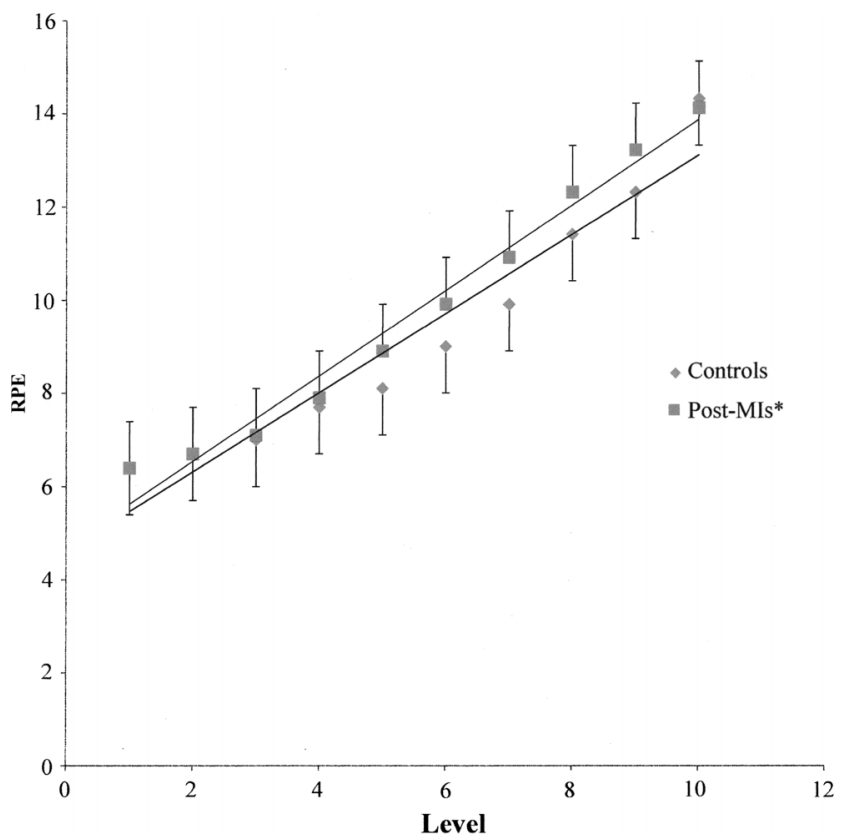

Figure 9 Ratings of perceived exertion versus modified shuttle walking test-level relationship between post-myocardial infarctions and controls during the cones protocol. 


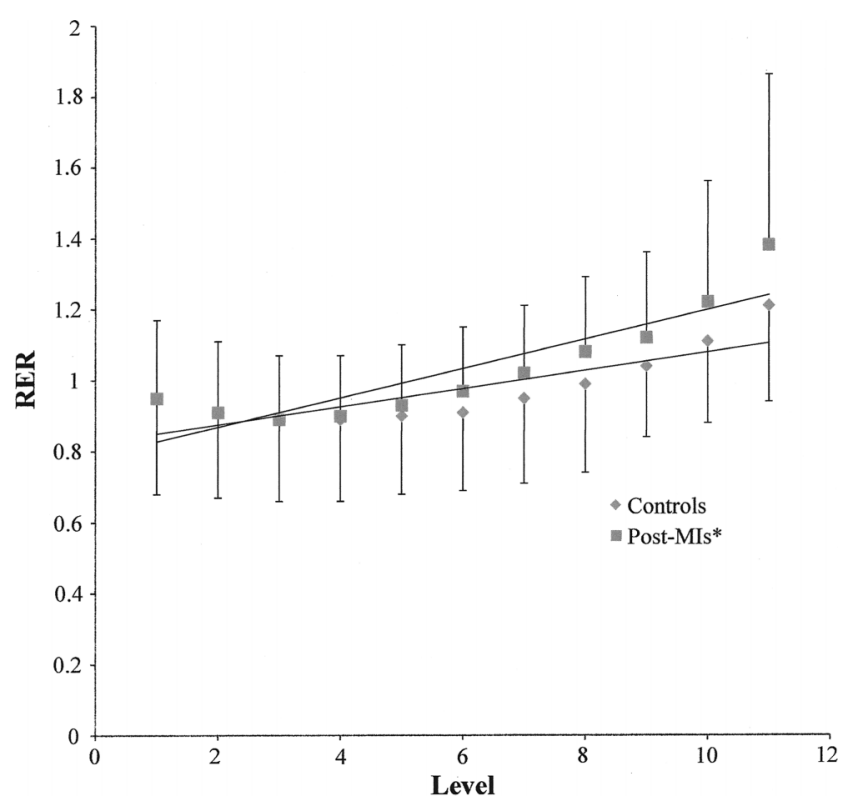

Figure 10 Respiratory exchange ratio versus modified shuttle walking test-level relationship between post-myocardial infarctions and controls during the no-cones protocol.

health risk for cardiac patients working at the higher end of their AT as this can result in functional impairment and possible ischaemia. ${ }^{24}$ Therefore, in this context, keeping below AT without affecting in the $\mathrm{VO}_{2}$ peak would be beneficial for post-MIs. Interestingly, values of RPE did not differ between protocols for the post-MIs, who did report higher RPE values than controls, indicating that they found both protocols more difficult.

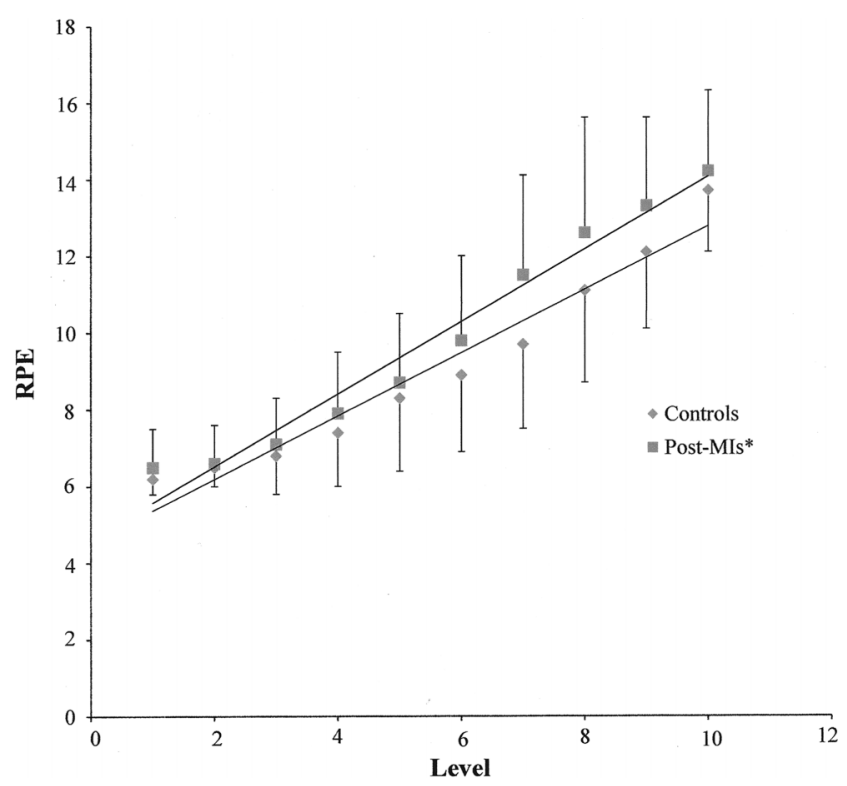

Figure 11 Ratings of perceived exertion versus modified shuttle walking test-level relationship between post-myocardial infarctions and controls during the no-cones protocol.
Despite no statistically significant differences being observed in the $\mathrm{VO}_{2}$ peak between protocols or groups, there was a significant difference in the $\mathrm{VO}_{2}$ versus MSWT shuttle-level (walking speed) relationship between the protocols before the groups were differentiated. Secondary analysis revealed that this was due to the steepness of the trajectory of the lines of regression rather than the difference in the $\mathrm{VO}_{2}(\mathrm{ml} / \mathrm{kg} / \mathrm{min})$ values at each level per se. However, during the no-cones, it was the post-MIs who consistently showed a higher $\mathrm{VO}_{2}$ versus MSWT shuttle-level (walking speed) relationship, which was not seen in the controls. Interestingly, Roberts $e t a l^{25}$ observed that during treadmill testing, healthy and coronary artery disease (CAD) patients, at any given workload below AT, produced similar $\mathrm{VO}_{2}$ values. Yet, at workloads beyond AT, CAD patients produced lower $\mathrm{VO}_{2}$ values than their healthy controls. This, however, was not observed between the post-MIs and controls of this study.

HR values were significantly lower at pre-test rest and during both protocols for post-MIs compared with controls, which was most likely due to the $\beta$-blockers. Nineteen $(95 \%)$ post-MIs were taking this drug, which is standard prescription post-MI. ${ }^{26}$ This drug not only alters cardiorespiratory response (slower HR) but can also slow down oxygen kinetics. ${ }^{27}{ }^{28}$ Evidence indicates that $\beta$-blockers can reduce skeletal muscle blood flow and thus increase general fatigue. ${ }^{29-32}$ The very same participants that took $\beta$-blockers were also taking statins, which produced a similar statistical result. High doses of statins can lead to muscle myopathy and interfere with fatty acid oxidation, producing greater oxidation of carbohydrates. ${ }^{33}$ Given that the post-MIs on statins were on relatively low doses $(40 \mathrm{mg})$, it is unlikely that the statins had any such effect. However, similar depressive effects on lipolysis have been found from $\beta$-blockers. ${ }^{34} 35$ These factors might partly explain why post-MIs reported higher RPE values during both protocols, though there was no difference in RER or $\mathrm{VO}_{2}$ values between groups. It has been reported that $\beta$-blockers do not affect RPE in clinical groups ${ }^{36-38}$ and do not tend to influence unless exercise is longer than $60 \mathrm{~min}$ and/or at an intensity higher than $65 \% \mathrm{VO}_{2}$ max. ${ }^{30} 31$ This exercise intensity would most likely have been achieved during the latter stages of either MSWT protocol and might therefore explain the heteroscedasticity observed in RPE between groups (see figure 6).

The current cones version of MSWT has been shown to correlate highly with peak $\mathrm{VO}_{2}$ during treadmill tests in a range of different cardiac ${ }^{11} 3940$ and respiratory populations. ${ }^{41}$ In our previous work, ${ }^{16}$ a group of noncardiac males $(\mathrm{n}=19,64.6 \pm 7.5$ years $)$ performed both MSWT without the cones and a treadmill test of the same protocol. Here too, the limits of agreement analysis ${ }^{42}$ showed acceptability between the treadmill and no-cones MSWT in $\mathrm{VO}_{2}\left(\mathrm{ml} / \mathrm{kg}^{-1} / \mathrm{min}\right.$ ) (mean difference $-1.1 \pm 8.8$ (1.96 SD), CI 7.7 to 9.9$)$, reflected by a strong correlation $\left(\mathrm{R}=0.88, \quad \mathrm{R}^{2}=0.48, \quad \mathrm{p}<0.001\right)$. The 
findings therefore indicate that the no-cones version of MSWT correlates as strongly as the cones version with treadmill tests for non-cardiac participants. The next stage would obviously be to repeat this in a group of cardiac patients. Additionally, although the learning and order effect had been accounted for within this study, test-retest repeatability was not. In order for the no-cones version to be reliably employed, both these factors require to be determined in future research.

In conclusion, it is clear that additional research is required before the no-cones version of MSWT can be reliably adopted. However, the findings of this study indicate that despite post-MIs finding both protocols subjectively harder than the non-cardiac controls, both groups work at a lower percentage of their AT during the no-cones protocol with no significant effect upon the $\mathrm{VO}_{2}$ peak. Therefore, in the context of $\mathrm{CR}$, the no-cones protocol would allow the patient to perform MSWT with less risk of functional impairment.

Contributors KWM conceived the idea of the study and was responsible for the study design and gaining ethical clearance, data analysis and produced the tables and graphs. SM was responsible for data collection and provided input into the study design. KWM was the lead writer and both the authors KWM and SM were involved in report writing and approved the final manuscript.

Funding This research received no specific grant from any funding agency in the public, commercial or not-for-profit sectors.

Competing interests None.

Patient consent Obtained.

Ethics approval The Faculty of Social and Applied Science Research Ethics Committee at Canterbury Christ Church University, reference 10/SAS/045.

Provenance and peer review Not commissioned; externally peer reviewed.

Data sharing statement The data regarding resting oxygen uptake are available by emailing the first author.

\section{REFERENCES}

1. Scottish Intercollegiate Guidelines Network (SIGN). Cardiac rehabilitation: a national clinical guideline. Guideline 57. Edinburgh: SIGN, 2002. http://www.sign.ac.uk/pdf/sign57.pdf

2. The Association of Chartered Physiotherapists in Cardiac Rehabilitation (ACPICR). Standards for physical activity and exercise in the cardiac population. 2009. http://acpicr.com/publications

3. British Association of Cardiac Prevention and Rehabilitation (BACPR). The BACPR standards and core components for cardiovascular disease prevention and rehabilitation. 2nd edn. London: BACPR, 2012

4. American Association of Cardiovascular and Pulmonary Rehabilitation (AACVPR). Guidelines for cardiac rehabilitation \& secondary prevention programs. 4th edn. Illinois: Human Kinetics, 2004

5. Blair SN, James PED, Kampert B, et al. Influences of cardiorespiratory fitness and other precursors on cardiovascular disease and all-cause mortality in men and women. JAMA 1996;276:205-10.

6. Farrell SW, Kampert JB, Kohl HW, et al. Influences of cardiorespiratory fitness levels and other predictors on cardiovascular disease mortality in men. Med Sci Sports Exerc 1998;30:899-905

7. Myers J, Goebbels U, Dzeikan G, et al. Exercise training and cardiac remodelling in patients with reduced ventricular function: one year follow-up with magnetic resonance imaging. Am Heart $J$ 2000;139:252-61.

8. Singh SL, Morgan MD, Scott S, et al. Development of a shuttle walking test of disability in patients with chronic airways obstruction. Thorax 1992;47:1019-24.
9. Tobin D, Thow MK. The $10 \mathrm{~m}$ shuttle walk test with Holter monitoring: an objective outcome measure for cardiac rehabilitation. Coron Health Care 1999;3:3-17.

10. Arnott AS. Assessment of functional capacity in cardiac rehabilitation: reproducibility of a $10-\mathrm{m}$ shuttle walk test. Coron Health Care 1997;1:30-6.

11. Fowler SJ, Singh SJ, Revill S. Reproducibility and validity of the incremental shuttle walking test in patients following coronary artery bypass surgery. Physiotherapy 2005;91:22-7.

12. Payne GE, Skehan JD. Shuttle walking test: a new approach for evaluating patients with pacemakers. Heart 1996;75:414-18.

13. Green DJ, Watts K, Rankin S, et al. A comparison of the shuttle and 6 minute walking tests with measured peak oxygen consumption in patients with heart failure. JSMS 2001;4:292-300.

14. Morales FJ, Montemayor T, Martinez A. Shuttle versus six-minute walk test in the prediction of outcome in chronic heart failure. Int $J$ Cardiol 2000;76:101-5.

15. Keell SD, Chambers JS, Francis DP, et al. Shuttle-walk test to assess chronic heart failure. Lancet 1998;352:705.

16. Woolf-May K, Ferrett $D$. Metabolic equivalents during the 10-metre shuttle-walking test for post-Ml patients. BJSM 2008;42:36-41.

17. Young ME, Razeghi $P$, Cedars $A M$, et al. Intrinsic diurnal variations in cardiac metabolism and contractile function. Circ Res 2001;89:1199-208.

18. Borg GA. Psychophysical bases of perceived exertion. Med Sci Sports Exerc 1982;14:377.

19. Davies LC, Wensel R, Georgiadou P, et al. Enhanced prognostic value from cardiopulmonary exercise testing in chronic heart failure by non-linear analysis: oxygen uptake efficiency slope. Eur Heart J 2006;27:684-90.

20. Keteyian SJ, Clinton A, Brawner MS, et al. Peak aerobic capacity predicts prognosis in patients with coronary heart disease. Am Heart J 2008; 156:292-300.

21. World Health Organisation (WHO). Global database on body mass index. http://apps.who.int/bmi/index.jsp?introPage=intro_3.html (accessed Nov 2012)

22. Wasserman K, Mcllroy MB. Detecting the threshold of anaerobic metabolism in cardiac patients during exercise. Am J Cardiol 1964;14:844-52.

23. Solberg G, Robstad B, Skjonsberg OH, et al. Respiratory gas exchange indices for estimating the anerobic threshold. Sport Sci Med 2005;4:29-36.

24. Fortini A, Bonechi F, Taddei T, et al. Anaerobic threshold in patients with exercise-induced myocardial ischemia. Circulation 1991;83:11150-3.

25. Roberts MJ, Sullivan M, Froelicher VF, et al. Predicting oxygen uptake from treadmill testing in normal subjects and coronary artery disease patients. Am Heart J 1984;108:1454-60.

26. National Institute of Clinical Excellence (NICE). Post myocardial infarction: secondary prevention in primary and secondary care for patients following a myocardial infarction. Full Guidelines CG48, 2007. http://www.nice.org.uk/nicemedia/live/11008/30493/30493.pdf

27. Hughson RL, Smyth GA. Slower adaptation of $\mathrm{VO}_{2}$ to steady state of submaximal exercise with beta-blockade. Eur J Appl Physiol 1983;52:107-10.

28. Reents S. Sport and exercise pharmacology. Champaign, Illinois: Human Kinetics, 2000.

29. Hall PE, Kendall MJ, Smith SR. Beta blocker and fatigue. J Clin HosPharm 1984;9:283-91.

30. Eston RG, Connolly D. The use of ratings of perceived exertion for exercise prescription in patients receiving $\beta$-blocker therapy. Sports Med 1996;21:176-90.

31. Head A, Maxwell S, Kendall MJ. Exercise metabolism in healthy volunteers taking celiprolol, atenolol, and placebo. BJSM 1997;31:120-5.

32. Lamont LS, Romito RC, Finkelhor RS, et al. Beta1-adrenoreceptors regulate resting metabolic rate. Med Sci Sports Exerc 1997;29:769-74.

33. Moosmann B, Behl C. Selenoprotein synthesis and side effects of statins. Lancet 2004;363:892-4.

34. Deacon SP. The effect of atenolol and propranolol upon lipolysis. Brit J Clin Pharmacol 1978;5:123-5.

35. Karlsson J. Metabolic adaptation to exercise: a review of potential beta-adrenoceptor antagonistic effects. Am J Cardiol 1985;55:48D-58D.

36. Davies CT, Sargeant AJ. The effects of atropine and practolol on the perception of exertion during treadmill exercise. Ergonomics 1979;22:1141-6.

37. Sjoberg H, Frankenhaeuser M, Bjurstedt $\mathrm{H}$. Interactions between heart rate, psychomotor performance and perceived effort during physical work as influenced by beta-andrenergic blockade. Biol Psychol 1979;8:31-43.

38. van Herwarden CL, Binkhorst RA, Fennis JF, et al. Effects of propranolol and metoprolol on haemodynamic and respiratory indices and on perceived exertion during exercise in hypertensive patients. Br Heart J 1979;41:99-105. 
39. Lewis ME, Newall JN, Townend SL, et al. Incremental shuttle walk test in the assessment of patients for heart transplantation. Heart 2001;86:183-7.

40. Green DJ, Watts K, Rankin S, et al. A comparison of the shuttle and 6 minute walking tests with measured peak oxygen consumption in patients with heart failure. J Sci Med Sport 2001;4:292-300.
41. Singh SL, Morgan MD, Hardman A, et al. Comparison of oxygen uptake during a conventional treadmill test and the shuttle walk test in chronic airflow limitation. Eur Resp J 1994;7:2016-20.

42. Bland JM, Altman D. Statistical methods for assessing agreement between two methods of clinical measurement. Lancet 1986;1:307-10. 